\title{
Heterogeneity of Platelet Alloantigens and Alloantibodies: New Insights into Structure and Function
}

\author{
Ines Socher ${ }^{a}$ Hartmut Kroll ${ }^{b}$ Sentot Santoso ${ }^{a}$

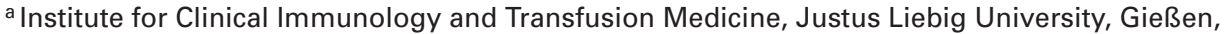 \\ ${ }^{b}$ German Red Cross Blood Transfusion Service NSTOB, Institute Dessau, Germany
}

\section{Key Words}

Alloantigens, human platelet: structure, function .

Thrombocytopenia, alloimmune

\section{Summary}

Human platelet alloantigens (HPAs) and their corresponding alloantibodies (alloabs) play an essential role in fetal and neonatal alloimmune thrombocytopenia, posttransfusion purpura and platelet transfusion refractoriness. Emerging genotyping methods (e.g. microarray technology) will allow an automated throughput for HPA typing of large donor cohorts in the near future. For the clinical diagnosis of alloimmune thrombocytopenia, however, the proof of pathogenic alloabs still remains a prerequisite. Nowadays, monoclonal antibody-based antigen capture assays are the state of the art in many laboratories. This technique seems to come up against limiting factors. In a certain number of cases that are highly suspicious for alloimmune thrombocytopenia, platelet-specific alloabs are not detectable. Current observations indicate that these alloabs are heterogeneous in terms of their alloantigenic determinants as well as the consequences on platelet function. This heterogeneity may correlate to the severe bleeding complications sometimes seen in patients with alloimmune thrombocytopenia. New insights on the role of pathogenic alloabs will help us to improve diagnostic and therapeutic approaches for the adequate treatment of affected patients.

\section{Introduction}

Immunization against human platelet alloantigens (HPAs) can induce several alloimmune thrombocytopenic syndromes with

\author{
Schlüsselwörter \\ Plättchenalloantigen, humanes: Struktur, Funktion \\ Thrombozytopenie, alloimmune
}

\section{Zusammenfassung}

Humane Plättchenalloantigene (HPA) und ihre Alloantikörper spielen eine bedeutende Rolle bei der fetalen und neonatalen Alloimmunthrombozytopenie, der posttransfusionellen Purpura und dem Refraktärzustand gegenüber Thrombozytentransfusionen. Die Einführung neuer Genotypisierungsverfahren (z.B. Microarray-Technologie) wird in der Zukunft eine Automatisierung der HPATypisierung erlauben. Dennoch ist der Nachweis thrombozytärer Antikörper nach wie vor unerlässlich für eine sichere klinische Diagnose. Heutzutage haben sich antigenspezifische Immunglobulintests (MAIPA) zu Referenztechniken entwickelt. Diese Methodik stößt jedoch an ihre Grenzen. In einer hohen Fallzahl mit dringendem Verdacht auf Alloimmunthrombozytopenie lassen sich thrombozytäre Alloantikörper nicht nachweisen. Neue Befunde weisen darauf hin, dass sich Alloantikörper sowohl in ihren Epitoperkennungsstellen als auch in ihren funktionellen Eigenschaften unterscheiden. Diese Heterogenität könnte im Zusammenhang zu den gelegentlich auftretenden schweren Blutungskomplikationen bei Patienten mit Alloimmunthrombozytopenie stehen. Eine Aufklärung der Bedeutung thrombozytärer Alloantikörper in der Pathogenese dieser Erkrankungen wird eine Verbesserung gegenwärtiger Diagnostik- und Therapieverfahren ermöglichen.

the clinical risk of severe bleeding. The serologic diagnosis of these syndromes is based on HPA typing and characterization of the corresponding platelet-specific alloantibodies (alloabs).

\begin{tabular}{ll}
\hline KARGER & ( ) 2006 S. Karger GmbH, Freiburg \\
Fax +497614520714 & Accessible online at: \\
$\begin{array}{l}\text { E-mail Information@Karger.de } \\
\text { www.karger.com }\end{array}$ & www.karger.com/tmh \\
&
\end{tabular}


Table 1. Molecular genetics of human platelet alloantigens

\begin{tabular}{|c|c|c|c|c|c|}
\hline Antigen & Synonym & Glycoprotein & HGNC & $\begin{array}{l}\text { Nucleotide } \\
\text { substitution }\end{array}$ & $\begin{array}{l}\text { Amino acid } \\
\text { substitution }\end{array}$ \\
\hline HPA-1a & $\mathrm{Zw}^{\mathrm{a}}, \mathrm{Pl}^{\mathrm{A} 1}$ & GPIIIa & ITGB3 & T176 & Leu33 \\
\hline HPA-1b & $\mathrm{Zw}^{\mathrm{b}}, \mathrm{Pl}^{\mathrm{A} 2}$ & & & $\mathrm{C} 176$ & Pro33 \\
\hline HPA-2a & $\mathrm{Ko}^{\mathrm{b}}$ & GPIba & GP1BA & $\mathrm{C} 482$ & Thr145 \\
\hline HPA-2b & $\mathrm{Ko}^{\mathrm{a}}, \mathrm{Sib}^{\mathrm{a}}$ & & & $\mathrm{T} 482$ & Met145 \\
\hline HPA-3a & $\mathrm{Bak}^{\mathrm{a}}, \mathrm{Lek}^{\mathrm{a}}$ & GPIIb & ITGA2B & $\mathrm{T} 2621$ & Ile843 \\
\hline HPA-3b & Bakb & & & $\mathrm{G} 2621$ & Ser843 \\
\hline HPA-4a & $\mathrm{Yuk}^{\mathrm{b}}, \mathrm{Pen}^{\mathrm{a}}$ & GPIIIa & ITGB3 & G506 & Arg143 \\
\hline HPA-4b & Yuk $^{\mathrm{a}}$, Pen $^{\mathrm{b}}$ & & & A506 & $\mathrm{Gln} 143$ \\
\hline HPA-5a & $\mathrm{Br}^{\mathrm{b}}, \mathrm{Zav}^{\mathrm{b}}$ & GPIa & ITGA2 & G1600 & Glu505 \\
\hline HPA-5b & $\mathrm{Br}^{\mathrm{a}}, \mathrm{Zav}^{\mathrm{a}}, \mathrm{Hc}^{\mathrm{a}} \mathrm{a}$ & & & A1600 & Lys505 \\
\hline HPA-6w & $\mathrm{Ca}^{\mathrm{a}}, \mathrm{Tu}^{\mathrm{a}}$ & GPIIIa & ITGB3 & $1544 \mathrm{G}>\mathrm{A}$ & Arg489Gln \\
\hline HPA-7w & $\mathrm{Mo}^{\mathrm{a}}$ & GPIIIa & ITGB3 & $1297 \mathrm{C}>\mathrm{G}$ & Pro407Ala \\
\hline HPA- $8 w$ & $\mathrm{Sr}^{\mathrm{a}}$ & GPIIIa & ITGB3 & $1984 \mathrm{C}>\mathrm{T}$ & Arg636Cys \\
\hline HPA-9w & $\operatorname{Max}^{\mathrm{a}}$ & GPIIb & ITGA2B & $2602 \mathrm{G}>\mathrm{A}$ & Val837Met \\
\hline HPA-10w & $\mathrm{La}^{\mathrm{a}}$ & GPIIIa & ITGB3 & $263 \mathrm{G}>\mathrm{A}$ & Arg62Gln \\
\hline HPA-11w & $\mathrm{Gro}^{\mathrm{a}}$ & GPIIIa & ITGB3 & $1976 \mathrm{G}>\mathrm{A}$ & Arg633His \\
\hline HPA-12w & $\mathrm{Iy}^{\mathrm{a}}$ & GPIbb & GP1BB & $119 \mathrm{G}>\mathrm{A}$ & Gly15Glu \\
\hline HPA-13w & $\mathrm{Sit}^{\mathrm{a}}$ & GPIa & ITGA2 & $2483 \mathrm{C}>\mathrm{T}$ & Thr799Met \\
\hline HPA-14w & $\mathrm{Oe}^{\mathrm{a}}$ & GPIIIa & ITGB3 & 1909_1911delAAG & Lys611del \\
\hline HPA-15a & Gov $^{\mathrm{b}}$ & CD109 & CD109 & $\mathrm{C} 2108$ & Ser682 \\
\hline HPA-15b & Gova $^{\mathrm{a}}$ & & & A2108 & Tyr2108 \\
\hline HPA-16w & Duv $^{\mathrm{a}}$ & GPIIIa & ITGB3 & $497 \mathrm{C}>\mathrm{T}$ & Thr140Ile \\
\hline
\end{tabular}

HGNC $=$ Human Gene Nomenclature Committee.

Table 2. Antibody specificities in serologically verified cases of FNAIT (Gießen, 1987-2002, $\mathrm{n}=569$ )

\begin{tabular}{lc}
\hline HPA- & Cases, $\mathrm{n}(\%)$ \\
\hline $1 \mathrm{a}$ & $428(75.1)$ \\
$5 \mathrm{~b}$ & $101(17.7)$ \\
$1 \mathrm{a}+5 \mathrm{~b}$ & $13(2.3)$ \\
$3 \mathrm{a}$ & $10(1.8)$ \\
$1 \mathrm{~b}$ & 3 \\
$2 \mathrm{~b}$ & 3 \\
$4 \mathrm{~b}$ & 1 \\
$5 \mathrm{a}$ & 2 \\
$8 \mathrm{w}$ & $1+1^{*}$ \\
$11 \mathrm{w}$ & 1 \\
$12 \mathrm{w}$ & 1 \\
$13 \mathrm{w}$ & 2 \\
$14 \mathrm{w}$ & 1 \\
$15 \mathrm{~b}$ & 2 \\
\hline
\end{tabular}

* 1 additional case of anti-HPA- 8 w without FNAIT was observed.
During the last years, several molecular biological methods were developed for HPA typing, which allow reliable and fast determination of platelet allotypes $[1,2]$. In contrast, the detection of alloabs is technically still challenging. Nowadays, monoclonal antibody (mab)-based antigen capture assays (MAIPA) represent the standard technique for platelet alloabs testing [3, 4]. However, in a certain number of cases that are highly suspicious for alloimmune thrombocytopenia, platelet-specific alloabs are not detectable [5-7]. Another interesting aspect is the heterogeneity of the clinical presentation of alloimmune thrombocytopenic syndromes varying from mild thrombocytopenia to severe, sometimes life-threatening bleeding [7]. Until now, the reasons for this heterogeneous clinical picture are not well understood. Over the last years, evidence has accumulated that platelet-specific alloabs are heterogeneous in several ways. The binding region of HPA-1a alloabs on $\alpha \operatorname{IIb} \beta 3$ integrin differs from one individual to another [8], and platelet function impairment due to alloabs has been observed. The epitope heterogeneity may influence platelet antibody testing and may also cause platelet function deficits that are responsible for pronounced bleeding. The purpose of this review is to highlight recent data about heterogeneity of platelet-specific alloabs.

\section{Human Platelet Alloantigens}

The currently known HPAs are listed in table 1 [9]. So far, 6 diallelic alloantigen systems (HPA-1, -2, -3, -4, -5 and -15) and 10 low-frequency HPAs have been discovered. They are located on the platelet membrane glycoproteins (GPs) GPIa/IIa ( $\alpha 2 \beta 1$ integrin), GPIIb/IIIa ( $\alpha I I b \beta 3$ integrin), GPIb/IX and CD109. Almost all HPAs are formed by single missense mutations of the respective gene. Only HPA-14w is formed by a single amino acid deletion (Lys611) of the $\beta 3$ integrin subunit [10]. 
Fig. 1. Structural

features of the

integrin $\alpha \operatorname{IIb} \beta 3$.

A Ribbon diagram of crystallized structure of $\alpha$ IIb (blue) and $\beta 3$ (red). All domains are indicated.

B Ribbon diagram of PSI domain with a 2 -stranded $\beta$-sheet (red) flanked by 2 helices (blue). The hybrid domain is inserted into the last loop of PSI. The positions of Leu33Pro mutation (HPA-1) at the $\mathrm{AB}$ loop of the PSI domain and Arg93Gln mutation at the hybrid A'B loop hybrid domain are indicated. Disulfide bridge between Cys 13 -Cys 435 forms the long interstrand AB loop of the PSI domain (adapted from [31]).
A

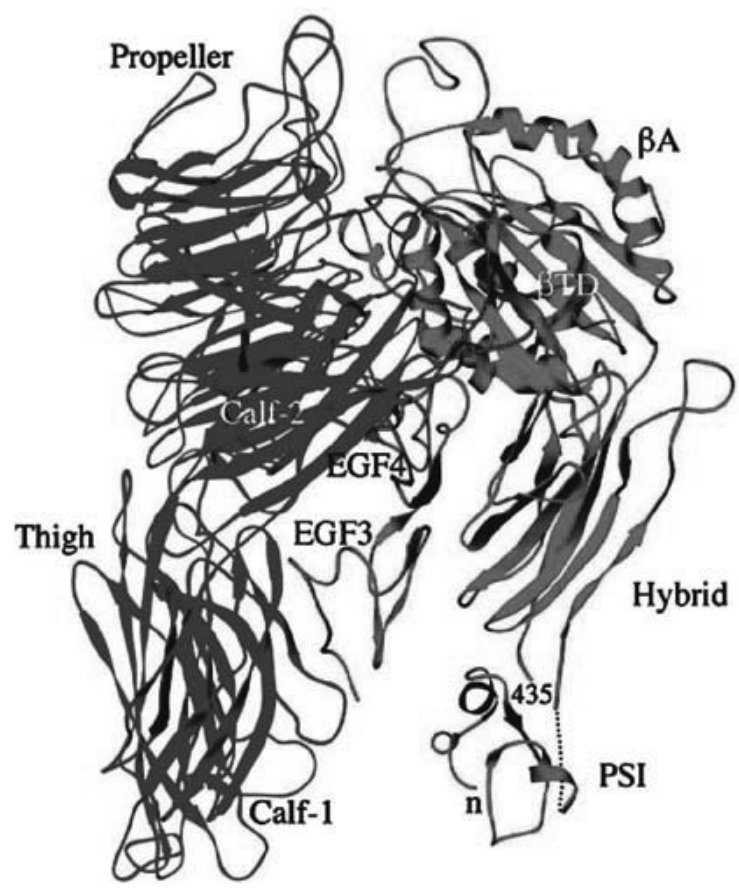

\section{Alloimmune Thrombocytopenic Syndromes}

HPAs are involved in 3 major clinical syndromes: fetal and neonatal alloimmune thrombocytopenia (FNAIT), posttransfusion purpura (PTP) and platelet transfusion refractoriness (PTR). FNAIT results from feto-maternal HPA incompatibility. Maternal $\mathrm{IgG}$ antibodies cross the placenta and mediate the destruction of fetal platelets. In the white population, alloimmunization against HPA-1a is the major cause of FNAIT accounting for $75 \%$ of all serologically verified cases [11]. Anti-HPA-1a may lead to intracranial hemorrhage in 10-20\% of cases, half of which occur already in utero [7]. No predictors for severe bleeding complications have been identified except for the history of older siblings, indicating that the individual nature of the antibody is crucial for the clinical expression of FNAIT [12]. The second most frequent antigen involved in FNAIT is HPA-5b. Interestingly, FNAIT due to HPA-5b alloabs is usually milder than FNAIT due to anti-HPA-1a [13]. This observation indicates that epitope and/or antigen specificity of alloabs is closely related to clinical presentation, which was one of the first points that triggered our interest in antibody heterogeneity associated with alloimmune thrombocytopenia. Anti-HPA-3a, which is involved in at least $1-2 \%$ of cases, usually causes severe FNAIT [14]. In contrast, the clinical relevance of anti-HPA-15 alloabs for FNAIT is not yet clear [15]. The frequency of all other HPA alloabs is too low to estimate a clear relationship between specificity and clinical consequence. Recent reports suggest that HPA-9w may be more important for FNAIT than previously suspected [16, 17]. It will be interesting to study how the clinical presentation of HPA-9w and HPA-3 alloabs compare, since the underlying polymorphisms are located closely to each other. Table 2 summarizes the specificities of HPA alloabs in serologically verified cases of FNAIT which we diagnosed over a 16-year period [11]. Future studies and registries will focus on the development of predictors of clinical severity in immunizations against low-frequency HPAs. Recently, a novel murine model of FNAIT using $\beta 3$ integrin-deficient $\left(\beta 3^{-/}\right)$mice was established [18]. In this model, platelet antibodies against $\beta 3$ integrin produced the clinically relevant bleeding disorder as exhibited in human cases of FNAIT. One can hope that such models will help to obtain further insights into the pathogenic relevance of heterogeneous alloabs.

PTP is a rare transfusion reaction characterized by a sudden onset of thrombocytopenia most probably as a consequence of an anamnestic immune response to HPA-mismatched platelets or their fragments [19-20]. The mechanism by which alloabs (mostly anti-HPA-1a) are able to destroy autologous platelets is not yet fully understood. The frequency has been estimated to be 1/50,000 transfusions [21] but is constantly declining since the introduction of general leukodepletion of blood components. PTP is almost invariably associated with severe bleeding. 
Fig. 2. 'Switchblade' model of $\alpha \operatorname{IIb} \beta 3$ integrin structure. Integrins in the 'inactive state' form the highly flexible site 'genu' (arrow) which bends the integrin by $135^{\circ}$ forming a compact V-shaped structure ('bent conformer'). In the 'active state', the integrin is extended at the genu and forms a more linear shape ('extended conformer').

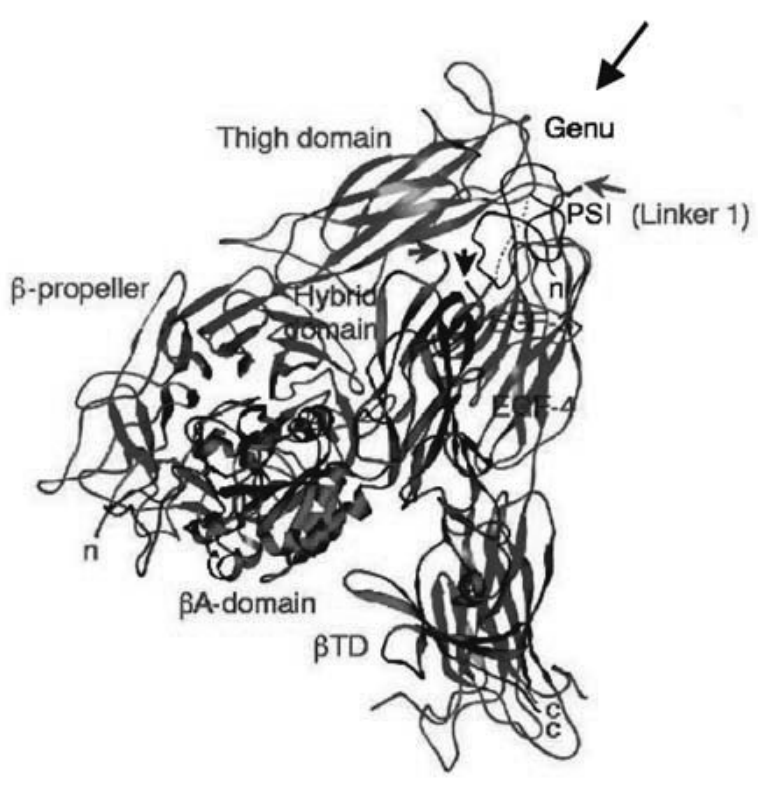

bent conformer „inactive state“

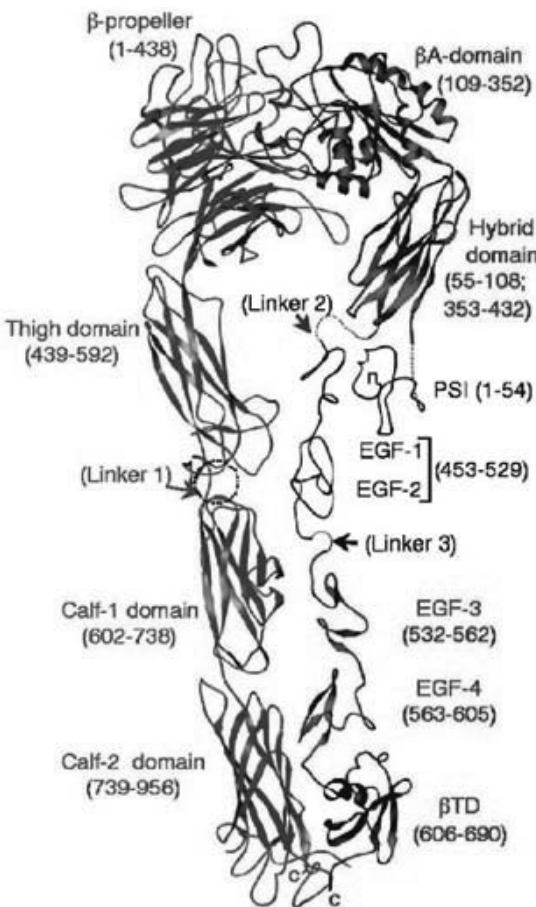

extended conformer „active state“
Immunogenic PTR is mostly caused by HLA-class I alloabs. In approximately $10 \%$ of HLA-immunized patients, additional platelet-specific alloabs have been observed, most frequently against HPA-1b and HPA-5b [22]. However, cases of PTR induced by platelet-specific alloabs alone are rare [22] and have been reported due to anti-HPA-1a [23, 24] and antiHPA-5b. Since many of the clinically most frequently involved HPAs are located on the $\alpha \operatorname{IIb} \beta 3$ integrin, we will focus in the following chapters on the structure-function relationship of HPAs residing on $\alpha \mathrm{IIb}$ and $\beta 3$.

\section{Integrin $\alpha$ llb $\beta 3$ and HPAs}

Integrins are a large family of heterodimeric receptors which are involved in cell-matrix and cell-cell adhesion interactions. Each subunit ( $\alpha$ and $\beta$ ) contains a large extracellular domain, a single-pass transmembrane domain and a short cytoplasmic tail [25]. Integrins are involved in numerous biological processes, such as development, angiogenesis, wound healing, neoplastic transformations and thrombosis [26-28].

The integrin $\alpha \operatorname{IIb} \beta 3$ is the major integrin on platelets. As adhesive for several ligands containing the RGD sequence (fibrinogen, fibronectin, vitronectin, collagen, von Willebrand factor), $\alpha \operatorname{IIb} \beta 3$ mediates platelet aggregation and platelet spreading on vascular matrices during hemostasis and arterial thrombosis. Recently, the crystal structure of $\alpha \operatorname{IIb} \beta 3$ was resolved
[29-31] (fig. 1). The $\alpha$ IIb subunit comprises of 4 domains: an aminoterminal 7-bladed propeller, an immunoglobulin-like 'thigh' domain and 2 co-linear $\beta$-sandwich domains (calf- 1 and calf-2). The $\beta 3$ subunit has 8 domains: an aminoterminal PSI (plexins, semaphorins, integrins) domain, an immunoglobulin (Ig)-like hybrid domain that contains the ligand-binding $\alpha \mathrm{A}$ like domain $(\beta \mathrm{A})$ inserted into the upper loops of the Ig-like hybrid domain. The hybrid domain is connected to 4 epidermal growth factor (EGF)-like domains and a novel $\beta$-tail domain ( $\beta$-TD). A key structural feature of the PSI domain is a distinctively long interstrand $\mathrm{AB}$ loop formed by $\mathrm{Cys}_{13}-\mathrm{Cys}_{435}$. This feature leads to interface interaction between the PSI and EGF-2 domain, which is important for the integrin activation process.

Integrin $\alpha \operatorname{IIb} \beta 3$ primarily functions as a bidirectional conduit for inside-out and outside-in signaling processes across the plasma membrane [32]. Inside-out signaling modulates $\alpha$ IIb $\beta 3$ conformation and transforms integrin into a high-affinity form (ligand-binding state). In turn, ligand-binding induces structural rearrangements conveying distinct signals to the cell interior (outside-in signaling). In one model ('switchblade' model, [33]), it was proposed that physiologic ligand binding requires straightening of the genu region (highly flexible site, fig. 2), thereby $\alpha \operatorname{IIb} \beta 3$ snaps from the bent conformer (inactive state) to the extended conformer (active state). However, it is more likely that a less drastic change is required for the initial transformation of $\alpha \operatorname{IIb} \beta 3$ integrin from the low- to the 


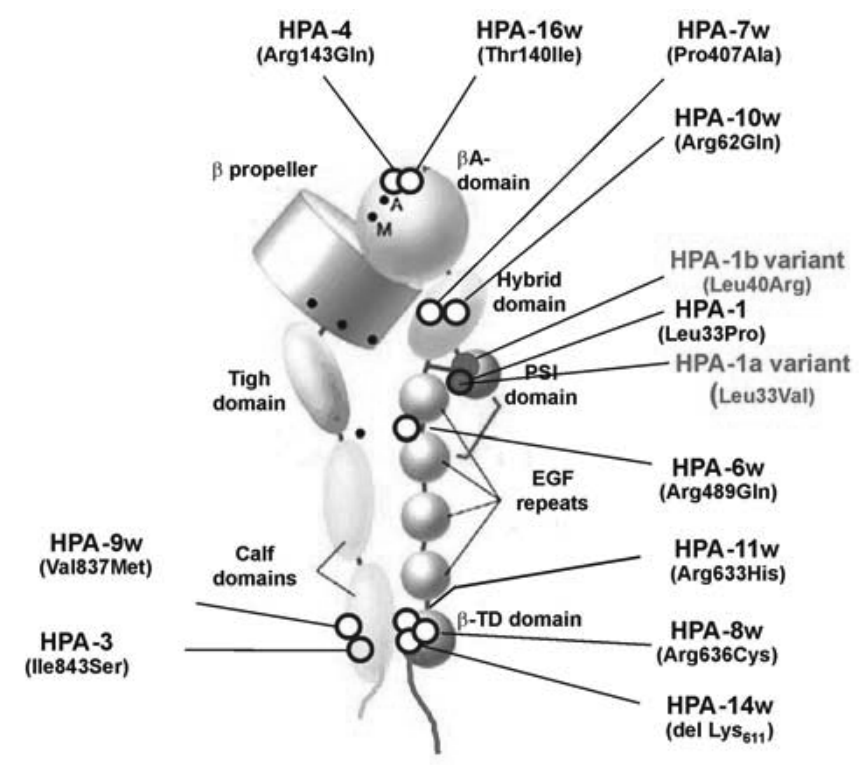

GPIlb-IIla $\left(\alpha_{\mathrm{IIb}} \beta_{3}\right)$

Fig. 3. Schematic diagram of natural occurring polymorphisms on $\alpha I I b \beta 3$ responsible for the formation of HPAs that can cause alloimmune thrombocytopenia. Two different polymorphisms, HPA-1b variant Leu40Arg and HPA-1a variant Leu33Val, with unknown implications in alloimmune thrombocytopenia are shown in red (adapted from [79]).

high-affinity state. The second model ('deadbolt' model [34]) proposed that inside-out signals transmit conformational changes through the transmembrane helices into the proximal $\beta$-TD of the $\beta 3$ integrin.

The identification of the domains in the integrin $\alpha \operatorname{IIb} \beta 3$ structure allows precise localization of HPAs (fig. 3). Whereas point mutations responsible for HPA-3 and HPA-9w located on $\alpha$ IIb subunit cluster on the calf-2 domain, no preferential domain for HPAs on the $\beta 3$ subunit can be observed. Within the ligand-binding $\beta A$ domain of $\beta 3$ (RGD binding domain), HPA-4 and HPA-16w are located. Other rare HPAs are distributed on the hybrid domain (HPA-7w, HPA-10w), EGF domain (HPA-6w) and $\beta$-TD domain (HPA-8w, HPA-11w and HPA-14w). The PSI domain harbors the clinically important point mutation Pro33Leu responsible for the formation of HPA-1a and HPA-1b, respectively. In addition, a variant of HPA-1b (Leu40Arg) and a new variant of HPA-1a (Leu33Val) were found in this domain (fig. 1). The elucidation of the PSI domain confirmed previous observations that this domain plays an important role for integrin activity [31]. Thus, replacement of Leu33 with Pro33 may alter $\alpha I I b \beta 3$ receptor activity in the binding of different ligands. In our current studies, we observed that a single amino acid substitution, Cys636, which directly forms HPA-8w, impaired cell aggregation to soluble fibrinogen (fig. 4). Since this mutation is located in the $\beta$-TD domain of $\beta 3$ integrin, we speculate that acti-

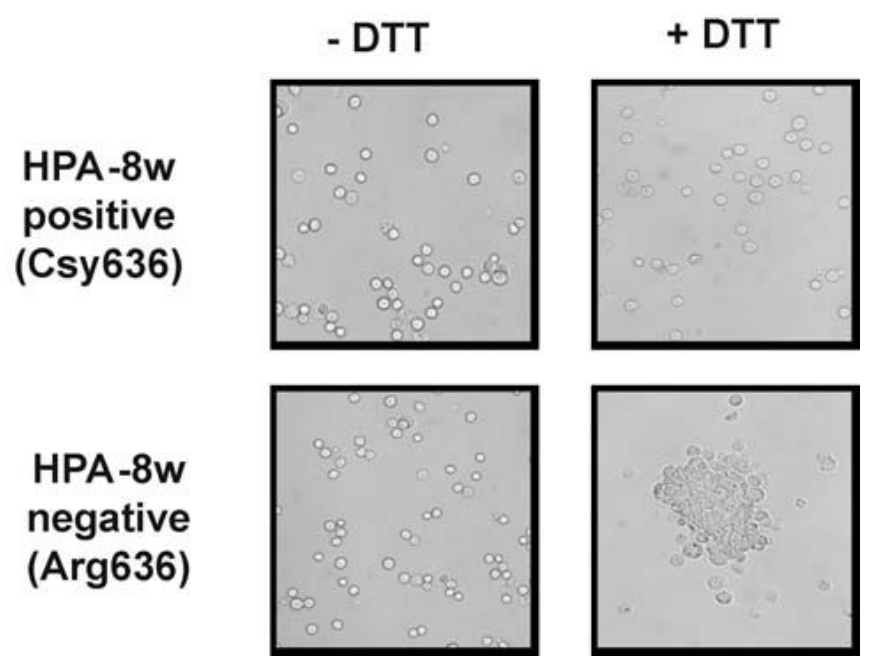

Fig. 4. Impaired cell aggregation to soluble fibrinogen due to point mutation Arg636Cys (HPA-8w). HPA-8w-negative (Arg636) and HPA-8wpositive (Cys636) transfected Chinese hamster ovary ( $\mathrm{CHO}$ ) cells were incubated with dithiothreitol (+DTT) to convert $\alpha \operatorname{IIb} \beta 3$ into an active conformer via disulfide bond reduction. In comparison to HPA- 8 w-negative cells, HPA-8w-positive cells showed loss of fibrinogen-induced aggregation. In the control experiment, untreated CHO cells (-DTT) did not show any aggregate formation.

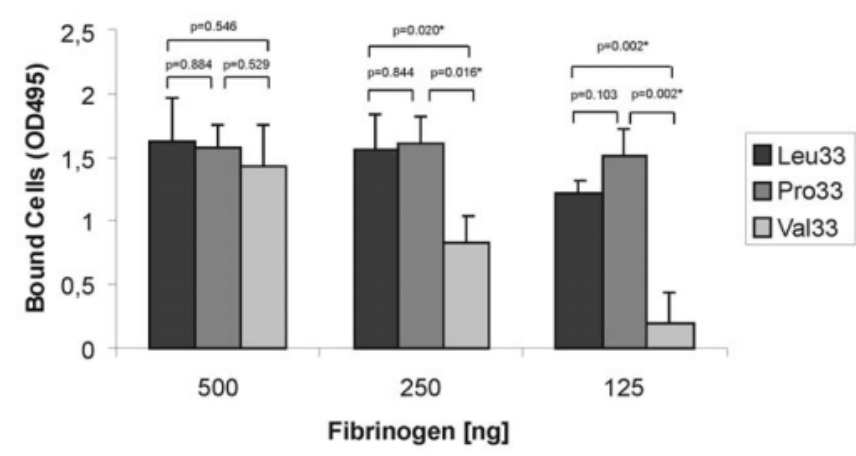

Fig. 5. Cell adhesion onto immobilized fibrinogen. $\beta 3$-Leu33- (HPA-1a), $\beta 3$-Pro33- (HPA-1b) and $\beta 3$-Val33-transfected CHO cells were allowed to adhere onto fibrinogen coated wells in the presence of serum-free culture medium. After washing, bound cells were stained and measured in a microtiter reader (OD $405 \mathrm{~nm}$ ). No significant difference was found between HPA-1a and HPA-1b in different fibrinogen concentrations. Please note that the adhesion capacity of $\beta 3$-Val33 was lower in comparison to both HPA-1a and HPA-1b transfectants when low (125 ng) and medium (250 ng) fibrinogen concentrations were applied.

vation via the 'deadbolt' mechanism during inside-out signaling is disturbed.

In the past years, increasing interest has focused on the impact of platelet polymorphisms on the development of acute coronary disease and cerebrovascular diseases $[35,36]$. Since the first report [37], several studies have investigated whether the HPA-1b allele confers a risk for atherothrombosis. Clinical 
Fig. 6. Principle of surface plasmon resonance (SPR) technology. Antibodies are lead through the flow channel. This results in a reduction of the angle of reflected flight as the antibody binds to immobilized antigen on the sensor chip. The angle shift can be computed as an increase in resonance units.

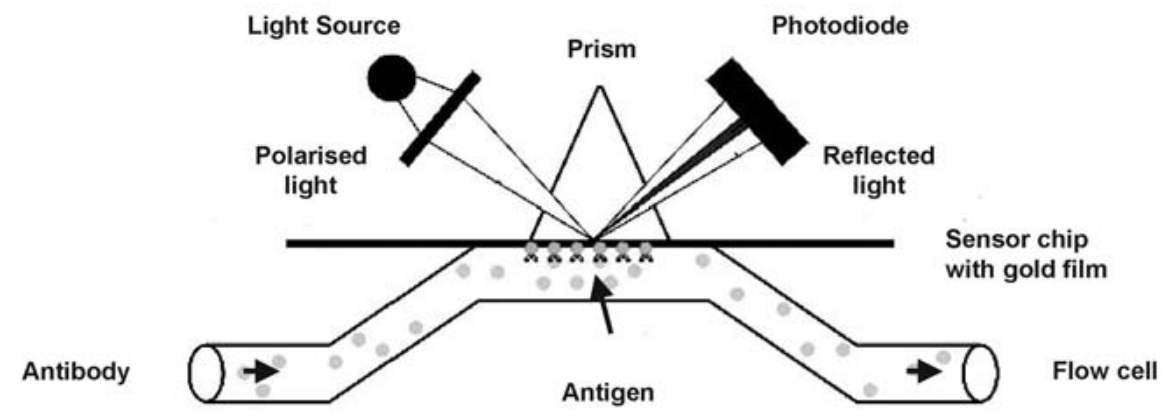

epidemiology studies resulted in contradictory findings [38]. However, a recent meta-analysis comprising a large cohort of patients $(\mathrm{n}=3,400)$ indicated that HPA-1b does confer a minor risk for coronary heart disease in comparison to controls $(n=3,500)$ [35]. Vijayan et al. [39] showed by using a model with transfected cells that HPA-1b bound significantly more to immobilized fibrinogen and exhibited a greater extent of cell spreading and clot retraction than HPA-1a cells. Recently, we established stable cell lines expressing Leu33 (HPA-1a), Pro33 (HPA-1b) and Val33 isoforms of the $\beta 3$ integrin. In contrast to the previous finding, we found no significant difference between HPA-1a and HPA-1b cell adhesion onto fibrinogen. Interestingly, the neutral point mutation Leu33Val altered cell adhesion more strongly than the Leu33Pro mutation (fig. 5). These results indicate that a point mutation at position 33 is indeed critical for platelet receptor function (see below).

\section{Heterogeneity of Platelet-Specific Alloantigenic Determinants}

Although the mutations that are responsible for the formation of platelet-specific alloantigens are well defined, the actual antibody recognition sites have not been precisely identified. These binding sites seem to be critically dependent on the 3-dimensional structure of the GP and on the contribution of carbohydrate residues. Furthermore, they seem to be heterogeneous. In the last years, several laboratories have attempted to produce synthetic or recombinant peptides that mimic platelet alloantigenic determinants. All attempts to construct HPA-1a epitopes using short linear or cyclic peptides (13-mer) straddling the $\mathrm{Leu}_{33}$ Pro dimorphism were unsuccessful [40, 41]. A small recombinant allelic $\beta 3$ protein (66 residues) seems to mimic HPA-1a epitopes [42, 43], however, some HPA-1a alloabs failed to recognize this fragment. Further studies demonstrated that the long-range disulfide bond ( Cys $\left._{13}-\mathrm{Cys}_{435}\right)$ is necessary for the structural integrity of the HPA-1a epitope [44-46]. Recently, Watkins et al. [47] showed that a naturally occurring Arg93Gln mutation in $\beta 3$ integrin disrupted the binding of HPA-1a alloabs. This mutation is lo- cated in the A'B loop of the hybrid domain [31] (fig. 1) which maintains the rigidity of the hybrid-PSI interface. The substitution of a positively charged arginine for glutamine at position 93 seems to alter this interface dramatically, leading to inaccessibility of HPA-1a alloabs.

Other findings demonstrated that the actual binding site of HPA-1a alloabs might be heterogeneous. Some HPA-1a alloabs bind the amino-terminal domain of $\beta 3$ integrin independently from the $\mathrm{Cys}_{13}$-Cys 435 bond, and others recognize combinatorial epitopes which require this long-range disulfide bridge [8]. Furthermore, Liu et al. [48] observed the existence of a split in HPA-1a alloab reactivity. Inhibition studies with mab LK-4 against $\beta 3$ integrin showed different HPA-1a alloab types: one that recognized the recombinant $\beta 3$ fragment (66 residues) and was sensitive to LK-4 inhibition, and another that bound to epitopes on the 66-residue fragment as well as on other regions of platelet $\beta 3$ integrin and was insensitive to LK-4 inhibition. Recently, we found the rare, naturally occurring point mutation Val33 on $\beta 3$ integrin (Santoso et al., Transfusion 2006, in press). Serological studies with different HPA1a alloabs indicated that Val33 defines a split in HPA-1a. When HPA-1a alloabs from FNAIT and PTP patients were tested, PTP sera recognized the $\beta 3$-Val33 isoform, whereas most FNAIT sera did not. This difference in reactivity may be related to differences in the nature of these diseases.

In contrast to HPA-1 epitopes [40], several studies have shown that carbohydrate residues contributed critically to the integrity of HPA-3a epitopes [49-51]. Djaffar et al. [52] demonstrated that presence of O-linked rather than $\mathrm{N}$-linked carbohydrate moieties preserves HPA-3a alloantigenic determinants. This observation is in line with the finding of Calvete et al. [53] who localized the precise site of O-glycosylation to GPIIb (Ser 847 ), which is only 4 amino acids away from the polymorphic residue 843 .

\section{Functional Heterogeneity of Platelet Alloantibodies}

There have been some reports that platelet reactive antibodies could influence platelet functions either by activating or inhibitory effects. Inhibitory antibodies against the integrin 


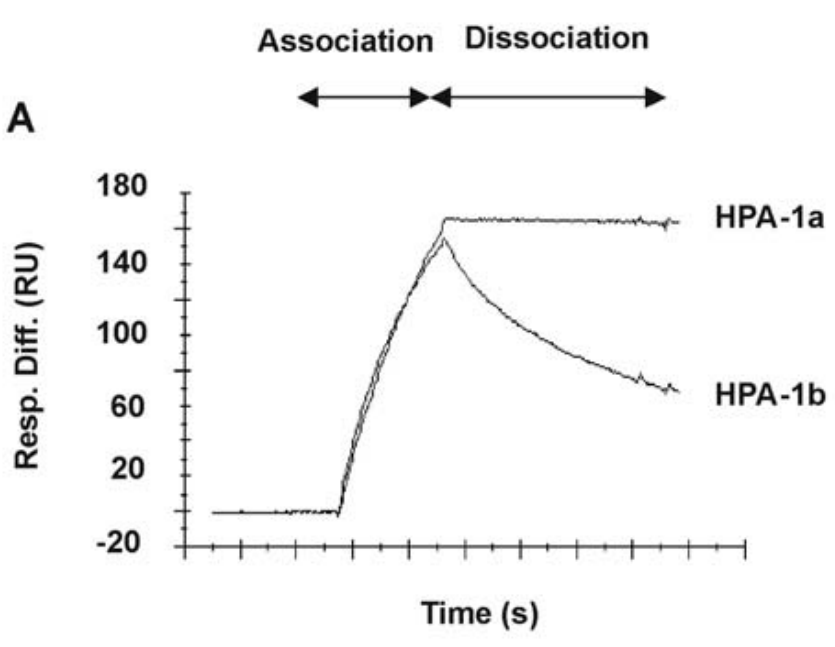

B

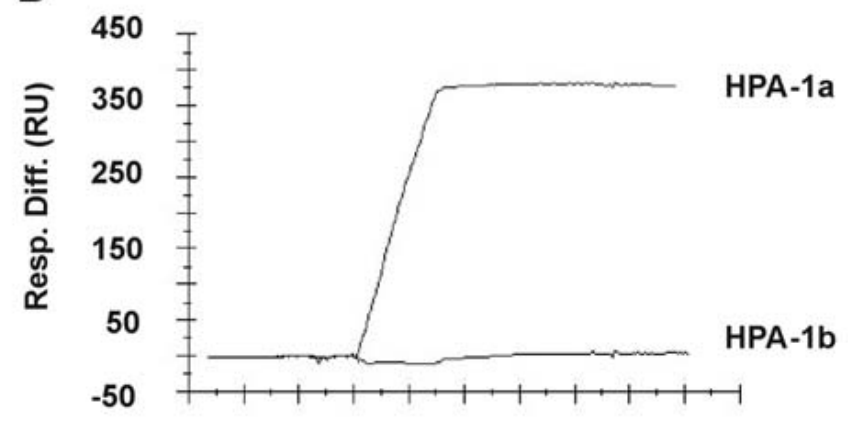

Time (s)

Fig. 7. Real-time analysis of mabs against HPA-1a and HPA-1b antigens Binding kinetics (association and dissociation) of abs was recorded as sensorgrams: relative response difference (resonance units) against time (s). The dissociation phase was followed for $130 \mathrm{~s}$. The remaining bound abs was calculated as the percentage of relative response at the beginning and the end of the dissociation phase. A Mab SZ21 associated with HPA-1a and HPA-1b. At the of the dissociation phase, only $49.5 \%$ of abs remained bound to HPA-1b. B Interaction between human mab CamTran007 against HPA-1a. Mab CamTran007 bound to HPA-1a remained associated with HPA-1a (100\%) at the end of the dissociation phase. No interaction was observed with HPA-1b.

$\alpha \mathrm{IIb} \beta 3$ may result in a hemorrhagic disorder similar to the situation in patients with $\alpha \mathrm{IIb} \beta 3$ deficiency (acquired Glanzmann's thrombasthenia) [54-57]. Other studies described platelet reactive antibodies that activate platelets by a Fc dependent mechanism, via the complement system or by direct occupation of platelet receptors [57]. Recently, Nardi et al. [58] described a novel mechanism of complement-independent platelet clearance in HIV-1-related immune thrombocytopenia. Binding of patient's IgG antibodies against platelet $\beta 3$ residues 49-66 caused platelet fragmentation by induction of reactive oxygen species in the absence of complement. Interestingly, antibodies directed neither against other regions of $\beta 3$ integrin nor against GPIb $\alpha$ failed to induce platelet frag- mentation. These findings indicated that only antibodies against specific regions of $\beta 3$ integrin are able to activate a peroxide-generating pathway.

Two decades ago, van Leeuwen et al. [59] showed that noncomplement fixing HPA-1a alloabs can inhibit fibrinogen binding and platelet aggregation in response to stimulation with agonists such as adenosine diphosphate and collagen. Since then, only limited data have been published [60, 61]. Studies are complicated by several factors that may influence processes of platelet activation. Many HPA-1a alloabs are accompanied by other platelet reactive antibodies, most frequently by HLA class I antibodies, which may also affect platelet function [62-64]. Since HPA-1a alloabs may recognize different functional epitopes, we sought to analyze the direct effect of different HPA- 1 a alloabs on $\alpha$ IIb $\beta 3$-mediated fibrinogen binding [65]. To prove the inhibitory effect of HPA-1a alloabs, transfected cells expressing HPA-1a or HPA-1b were incubated with sera from FNAIT and PTP patients and allowed to adhere to immobilized fibrinogen. Interestingly, 3 different patterns of reactivity were observed with alloabs showing i) no inhibition of cell adhesion, ii) allotype-specific inhibition (inhibition of HPA-1a cells only), and iii) non-allotype-specific inhibition (inhibition of both HPA-1a and HPA$1 \mathrm{~b}$ cells). Blocking HPA-1a alloabs were found in sera of FNAIT $(9.3 \%)$ and PTP (75\%) patients. In some cases of PTP, the inhibition of fibrinogen binding was found to be associated with severe bleeding, suggesting that HPA-1a alloabs may contribute to pronounced bleeding in patients with alloimmune syndromes. Thus, some HPA-1a alloabs can occupy platelet fibrinogen receptors, leading to 'thrombopathic thrombocytopenia' as observed in patients with acquired Glanzmann's thrombasthenia. However, further studies are necessary to explore the relevance of the different patterns in alloimmune-mediated thrombocytopenia.

\section{Platelet Antibody Detection: New Approach}

The specific and sensitive detection of platelet-specific alloabs is essential for adequate treatment of patients suffering from alloimmune thrombocytopenia. Several assays have been developed during the last 2 decades. Binding assays using whole platelets $[66,67]$ have limitations since they allow no discrimination between platelet-specific alloabs and HLA antibodies. This problem is encountered by the development of GP-specific assays (e.g. MAIPA) [3, 68]. Meanwhile, the MAIPA assay is the most widely used technique $[4,69,70]$. Recently, we established a panel of stable transfectants expressing lowfrequency HPAs, which can be used for alloab identification if the corresponding platelets are lacking [11]. Recombinant HPAs for serology are supplemented by reference DNA from B-lymphoblastoid cell lines for clinical diagnosis [71]. In some cases that are clinically highly suspicious for FNAIT, plateletspecific alloabs are not detectable by MAIPA assay [7, 72]. 
One major disadvantage of the MAIPA assay is the necessity of selected mouse mabs. As mouse mabs may compete with the binding of patients alloabs, false-negative results could be obtained [73]. Furthermore, excessive washing procedure in the MAIPA assay may result in dissociation of alloabs (lowavidity).

Surface plasmon resonance (SPR) technology, known as biomolecular interaction analysis, allows a visualization of antigen-antibody binding in real time, without the use of labeling or washing processes [74-77]. Recently, SPR technology has been applied to measure IgG anti-A and anti-B levels in patient plasma [78]. In SPR, one of the interacting partners (e.g. antigen) is immobilized on a sensor chip, and the binding of the other partner (e.g. antibody) is delivered to the surface in a continuous buffer flow (fig. 6). The sensor chip consists of a glass surface which is coated with a dextran-modified gold layer creating the physical requirements for SPR. The SPR phenomenon arises from the total internal reflection of the polarized light into a prism that occurs when the light passes between 2 media of different refractive index. Association of antibodies to the antigen results in a reduction of the reflected light intensity, whereas dissociation leads to an increase in the reflected light intensity. This reflection of light occurs at a specific angle (the resonance angle) which is measurable in SPR technology.

In preliminary studies, we analyzed the binding characteristics of different mabs against HPA-1a using SPR technology. Integrin $\alpha \operatorname{IIb} \beta 3$ was purified by affinity chromatography from platelets derived from homozygous HPA-1a/a or HPA-1b/b donors and immobilized on a sensor chip. Mouse and human mabs against HPA-1a (SZ21, CamTran007) were injected into the reaction chamber. Real-time HPA-1a antibody binding characteristics were recorded. As shown in figure 7, mab SZ21, which is known to bind HPA-1a preferentially, dissociated more rapidly from HPA-1b than from HPA-1a. In con- trast, human mab CamTran007, which was originally derived from a FNAIT mother, bound to HPA-1a but not to HPA-1b. Since SPR provides additional information on binding kinetics of HPA-1a antibodies in real-time, this technology may help to improve the diagnosis of platelet alloabs.

\section{Conclusions and Perspectives}

In the last years, several efforts have been made to optimize the genotyping method for HPAs. Now, the HPA microarray technology has become available which allows a reliable and fast genotyping procedure. In the near future, an automated throughput for complete typing of large donor cohorts can be obtained. For the diagnosis of alloimmune thrombocytopenia, however, the proof of pathogenic alloabs in patient sera is still indispensable. With the availability of well-defined mabs against platelet GPs, antigen-specific assays for alloab testing have become the state of the art. However, recent observations indicated a diversity of epitopes as well as structural and functional heterogeneity of alloabs. The introduction of functional assays (e.g. adhesion assay) and direct analysis of antigen-antibody interaction (e.g. by SPR technology) may help us to further characterize platelet-specific alloabs with respect to their clinical meaning. New insights into the pathogenesis will aid to develop diagnostic and therapeutic approaches for alloimmune thrombocytopenia. The identification of antibody-combining sites on platelet receptors might serve as a basis for future investigations.

\section{Addendum}

Some of the data presented in this review are part of the doctoral thesis of Ines Socher.

\section{References}

1 Beiboer SH, Wieringa-Jelsma T, Maaskant-Van Wijk PA, van der Schoot CE, van Zwieten R, Roos D, den Dunnen JT, de Haas M: Rapid genotyping of blood group antigens by multiplex polymerase chain reaction and DNA microarray hybridization. Transfusion 2005;45:667-679.

2 Bugert P, McBride S, Smith G, Dugrillon A, Kluter $\mathrm{H}$, Ouwehand WH, Metcalfe P: Microarray-based genotyping for blood groups: comparison of gene array and 5'-nuclease assay techniques with human platelet antigen as a model. Transfusion 2005;45: 654-659.

3 Kiefel V, Santoso S, Weisheit M, Mueller-Eckhardt C: Monoclonal antibody-specific immobilization of platelet antigens (MAIPA): a new tool for the identification of platelet-reactive antibodies. Blood 1987;70:1722-1726.

4 McMillan R, Tani P, Millard F, Berchtold P, Renshaw L, Woods VL Jr: Platelet-associated and plasma anti-glycoprotein autoantibodies in chronic ITP. Blood 1987;70:1040-1045.
5 Bussel JB, Zacharoulis S, Kramer K, McFarland JG, Pauliny J, Kaplan C: Clinical and diagnostic comparison of neonatal alloimmune thrombocytopenia to non-immune cases of thrombocytopenia. Pediatr Blood Cancer 2005;45:176-183.

6 Williamson LM, Hackett G, Rennie J, Palmer CR, Maciver C, Hadfield R, Hughes D, Jobson S, Ouwehand WH: The natural history of fetomaternal alloimmunization to the platelet-specific antigen HPA-1a (PlA1, Zwa) as determined by antenatal screening. Blood 1998;92:2280-2287.

7 Mueller-Eckhardt C, Kiefel V, Grubert A, Kroll H, Weisheit M, Schmidt S, Mueller-Eckhardt G, Santoso S: 348 cases of suspected neonatal alloimmune thrombocytopenia. Lancet 1989;i:363-366.

8 Valentin N, Visentin GP, Newman PJ: Involvement of the cysteine-rich domain of glycoprotein IIIa in the expression of the human platelet alloantigen, PIA1: evidence for heterogeneity in the humoral response. Blood 1995;85:3028-3033.
9 Metcalfe P, Watkins NA, Ouwehand WH, Kaplan C, Newman P, Kekomaki R, De Haas M, Aster R, Shibata Y, Smith J, Kiefel V, Santoso S: Nomenclature of human platelet antigens. Vox Sang 2003; 85:240-245.

10 Santoso S, Kiefel V, Richter IG, Sachs UJ, Rahman A, Carl B, Kroll H: A functional platelet fibrinogen receptor with a deletion in the cysteine-rich repeat region of the beta(3) integrin: the Oe(a) alloantigen in neonatal alloimmune thrombocytopenia. Blood 2002;99:1205-1214.

11 Kroll H, Yates J, Santoso S: Immunization against a low-frequency human platelet alloantigen in fetal alloimmune thrombocytopenia is not a single event: characterization by the combined use of reference DNA and novel allele-specific cell lines expressing recombinant antigens. Transfusion 2005; 45:353-358.

12 Birchall JE, Murphy MF, Kaplan C, Kroll H: European collaborative study of the antenatal management of feto-maternal alloimmune thrombocytopenia. Br J Haematol 2003;122:275-288. 
13 Kaplan C, Morel-Kopp MC, Kroll H, Kiefel V, Schlegel N, Chesnel N, Mueller-Eckhardt C: HPA$5 \mathrm{~b}(\mathrm{Br}(\mathrm{a}))$ neonatal alloimmune thrombocytopenia: clinical and immunological analysis of 39 cases. Br J Haematol 1991;78:425-429.

14 Glade-Bender J, McFarland JG, Kaplan C, Porcelijn L, Bussel JB: Anti-HPA-3A induces severe neonatal alloimmune thrombocytopenia. J Pediatr 2001;138:862-867.

15 Ertel K, Al-Tawil M, Santoso S, Kroll H: Relevance of the HPA-15 (Gov) polymorphism on CD109 in alloimmune thrombocytopenic syndromes. Transfusion 2005;45:366-373.

16 Peterson JA, Balthazor SM, Curtis BR, McFarland JG, Aster RH: Maternal alloimmunization against the rare platelet-specific antigen HPA-9b (Max a) is an important cause of neonatal alloimmune thrombocytopenia. Transfusion 2005;45:1487-1495.

17 Kaplan C, Porcelijn L, Vanlieferinghen P, Julien E, Bianchi F, Martageix C, Bertrand G, Jallu V: AntiHPA-9bw (Maxa) fetomaternal alloimmunization, a clinically severe neonatal thrombocytopenia: difficulties in diagnosis and therapy and report on eight families. Transfusion 2005;45:1799-1803.

18 Ni H, Chen P, Spring CM, Sayeh E, Semple JW, Lazarus AH, Hynes RO, Freedman J: A novel murine model of fetal and neonatal alloimmune thrombocytopenia: response to intravenous $\mathrm{IgG}$ therapy. Blood 2005;107:2976-2983.

19 Kroll H, Kiefel V, Mueller-Eckhardt C: Die Posttransfusionelle Purpura. Klinische und immunologische Untersuchungen bei 38 Patientinnen. Infusionsther Transfusionsmed 1993;20:198-204.

20 Mueller-Eckhardt C: Post-transfusion purpura. Br J Haematol 1986;64:419-424.

21 Williamson L, Cohen H, Love E, Jones H, Todd A, Soldan K: The Serious Hazards of Transfusion (SHOT) initiative: the UK approach to haemovigilance. Vox Sang 2000;78(suppl 2):291-295.

-22 Kiefel V, Konig C, Kroll H, Santoso S: Platelet alloantibodies in transfused patients. Transfusion 2001;41:766-770.

23 Novotny VM, van Doorn R, Witvliet MD, Claas FH, Brand A: Occurrence of allogeneic HLA and non-HLA antibodies after transfusion of prestorage filtered platelets and red blood cells: a prospective study. Blood 1995;85:1736-1741.

24 Pappalardo PA, Secord AR, Quitevis P, Haimowitz $\mathrm{MD}$, Goldfinger D: Platelet transfusion refractoriness associated with HPA-1a (PI(A1)) alloantibody without coexistent HLA antibodies successfully treated with antigen-negative platelet transfusions. Transfusion 2001;41:984-987.

25 Hynes RO: Integrins: bidirectional, allosteric signaling machines. Cell 2002;110:673-687.

26 Brooks PC, Clark RA, Cheresh DA: Requirement of vascular integrin alpha $\mathrm{v}$ beta 3 for angiogenesis. Science 1994;264:569-571.

27 DeSimone DW: Adhesion and matrix in vertebrate development. Curr Opin Cell Biol 1994;6:747-751.

28 Price DT, Loscalzo J: Cellular adhesion molecules and atherogenesis. Am J Med 1999;107:85-97.

29 Xiong JP, Stehle T, Diefenbach B, Zhang R, Dunker R, Scott DL, Joachimiak A, Goodman SL, Arnaout MA: Crystal structure of the extracellular segment of integrin alpha Vbeta3. Science 2001; 294:339-345.

30 Xiao T, Takagi J, Coller BS, Wang JH, Springer TA: Structural basis for allostery in integrins and binding to fibrinogen-mimetic therapeutics. Nature 2004;432:59-67.
31 Xiong JP, Stehle T, Goodman SL, Arnaout MA: A novel adaptation of the integrin PSI domain revealed from its crystal structure. J Biol Chem 2004; 279:40252-40254.

32 Shattil SJ, Newman PJ: Integrins: dynamic scaffolds for adhesion and signaling in platelets. Blood 2004; 104:1606-1615.

33 Takagi J, Petre BM, Walz T, Springer TA: Global conformational rearrangements in integrin extracellular domains in outside-in and inside-out signaling. Cell 2002;110:599-511.

34 Xiong JP, Stehle T, Goodman SL, Arnaout MA New insights into the structural basis of integrin ac tivation. Blood 2003;102:1155-1159.

35 Santoso S, Kunicki T: Platelet receptor polymorphisms and thrombotic risk. Ital Heart J 2001;2 811-815.

36 Santoso S: Platelet polymorphisms in thrombotic disorders. Transfus Clin Biol 2001;8:261-266.

37 Weiss EJ, Bray PF, Tayback M, Schulman SP, Kickler TS, Becker LC, Weiss JL, Gerstenblith G, Goldschmidt-Clermont PJ: A polymorphism of a platelet glycoprotein receptor as an inherited risk factor for coronary thrombosis. N Engl J Med 1996; 334:1090-1094.

38 Bray PF: Integrin polymorphisms as risk factors for thrombosis. Thromb Haemost 1999;82:337-344.

39 Vijayan KV, Goldschmidt-Clermont PJ, Roos C, Bray $\mathrm{PF}$ : The $\mathrm{Pl}(\mathrm{A} 2)$ polymorphism of integrin beta(3) enhances outside-in signaling and adhesive functions. J Clin Invest 2000;105:793-802.

40 Newman PJ, Martin LS, Knipp MA, Kahn RA: Studies on the nature of the human platelet alloantigen, PlA1: localization to a 17,000-dalton polypeptide. Mol Immunol 1985;22:719-729.

41 Flug F, Espinola R, Liu LX, SinQuee C, DaRosso R, Nardi M, Karpatkin S: A 13-mer peptide straddling the leucine33/proline33 polymorphism in glycoprotein IIIa does not define the PLA1 epitope. Blood 1991;77:1964-1969.

42 Bowditch RD, Tani PH, Halloran CE, Frelinger AL 3rd, McMillan R, Ginsberg MH: Localization of a PlA1 epitope to the amino terminal 66 residues of platelet glycoprotein IIIa. Blood 1992;79:559-562.

43 Barron-Casella EA, Kickler TS, Rogers OC, Casella JF: Expression and purification of functional recombinant epitopes for the platelet antigens, PlA1 and PlA2. Blood 1994;84:1157-1163.

44 Beer J, Coller BS: Evidence that platelet glycoprotein IIIa has a large disulfide-bonded loop that is susceptible to proteolytic cleavage. J Biol Chem 1989;264:17564-17573.

45 Kunicki TJ, Honda S, Dawson B, Honda Y, Ruan C Aster RH: The P1A alloantigen system is a sensitive indicator of the structural integrity of the amino-terminal domain of the human integrin beta 3 subunit. Blood Cells Mol Dis 1995;21:131-141.

46 Honda S, Honda Y, Bauer B, Ruan C, Kunicki TJ: The impact of three-dimensional structure on the expression of PlA alloantigens on human integrin beta 3. Blood 1995;86:234-242.

47 Watkins NA, Schaffner-Reckinger E, Allen DL, Howkins GJ, Brons NH, Smith GA, Metcalfe P, Murphy MF, Kieffer N, Ouwehand WH: HPA-1a phenotype-genotype discrepancy reveals a naturally occurring Arg93Gln substitution in the platelet beta 3 integrin that disrupts the HPA-1a epitope. Blood 2002;99:1833-1839.

48 Liu LX, Nardi MA, Casella JF, Karpatkin S: Inhibition of binding of anti-PLA1 antibodies to platelets with monoclonal antibody LK-4. Evidence for multiple PLA1 receptor sites on platelet GPIIIa. Blood 1996;88:3601-3607.
49 Santoso S, Kalb R, Walka M, Kiefel V, MuellerEckhardt C, Newman PJ: The human platelet alloantigens $\operatorname{Br}(\mathrm{a})$ and $\mathrm{Brb}$ are associated with a single amino acid polymorphism on glycoprotein Ia (integrin subunit alpha 2). J Clin Invest 1993;92: 2427-2432.

50 Goldberger A, Kolodziej M, Poncz M, Bennett JS, Newman PJ: Effect of single amino acid substitutions on the formation of the PlA and Bak alloantigenic epitopes. Blood 1991;78:681-687.

51 Take H, Tomiyama Y, Shibata Y, Furubayashi T, Honda S, Mizutani H, Nishiura T, Tsubakio T, Kurata $\mathrm{Y}$, Yonezawa $\mathrm{T}$, et al: Demonstration of the heterogeneity of epitopes of the platelet-specific alloantigen, Baka. Br J Haematol 1990;76:395-400.

52 Djaffar I, Vilette D, Pidard D, Wautier JL, Rosa JP: Human platelet antigen 3 (HPA-3): localization of the determinant of the alloantibody Lek(a) (HPA$3 \mathrm{a})$ to the $\mathrm{C}$-terminus of platelet glycoprotein $\mathrm{IIb}$ heavy chain and contribution of O-linked carbohydrates. Thromb Haemost 1993;69:485-489.

53 Calvete JJ, Muniz-Diaz E: Localization of an O-glycosylation site in the alpha-subunit of the human platelet integrin GPIIb/IIIa involved in Baka (HPA-3a) alloantigen expression. FEBS Lett 1993; 328:30-34.

54 Niessner H, Clemetson KJ, Panzer S, Mueller-Eckhardt C, Santoso S, Bettelheim P: Acquired thrombasthenia due to GPIIb/IIIa-specific platelet autoantibodies. Blood 1986;68:571-576.

55 Tholouli E, Hay CR, O'Gorman P, Makris M: Acquired Glanzmann's thrombasthenia without thrombocytopenia: a severe acquired autoimmune bleeding disorder. $\mathrm{Br} \mathrm{J}$ Haematol 2004;127: 209-213.

56 Deckmyn H, De Reys S: Functional effects of human antiplatelet antibodies. Semin Thromb Hemost 1995;21:46-59.

57 Deckmyn H, Vanhoorelbeke K, Peerlinck K: Inhibitory and activating human antiplatelet antibodies. Baillieres Clin Haematol 1998;11:343-359.

58 Nardi M, Tomlinson S, Greco MA, Karpatkin S: Complement-independent, peroxide-induced antibody lysis of platelets in HIV-1-related immune thrombocytopenia. Cell 2001;106:551-561.

59 Van Leeuwen EF, Leeksma OC, van Mourik JA, Engelfriet CP, von dem Borne AE: Effect of the binding of anti-Zwa antibodies on platelet function. Vox Sang 1984;47:280-289.

60 Duncan JR, Rosse WF: Alloantibody-induced platelet serotonin release is blocked by antibody to the platelet PLA1 antigen. Br J Haematol 1986;64 331-338.

61 Beadling WV, Herman JH, Stuart MJ, KeashenSchnell M, Miller JL: Fetal bleeding in neonatal alloimmune thrombocytopenia mediated by anti$\mathrm{PlAl}$ is not associated with inhibition of fibrinogen binding to platelet GPIIb/IIIa. Am J Clin Pathol 1995;103:636-641.

62 Christie DJ, Leja DN, Carlson DL, Swinehart CD Characterization of platelet activation induced by HLA antibodies associated with alloimmune thrombocytopenia. J Lab Clin Med 1993;121:437443.

63 Christie DJ, Swinehart CD: Human platelet activating antibodies. Semin Thromb Hemost 1992;18: 186-192.

64 Rubinstein E, Urso I, Boucheix C, Carroll RC: Platelet activation by cross-linking HLA class I molecules and Fc receptor. Blood 1992;79: 29012908 
65 Kroll H, Penke G, Santoso S: Functional heterogeneity of alloantibodies against the human platelet antigen (HPA)-1a. Thromb Haemost 2005;94:1224 1229.

66 Von dem Borne AE, Verheugt FW, Oosterhof F, von Riesz E, de la Riviere AB, Engelfriet CP: A simple immunofluorescence test for the detection of platelet antibodies. Br J Haematol 1978;39:195207.

67 Schneider W, Schnaidt M: The platelet adhesion immunofluorescence test: a modification of the platelet suspension immunofluorescence test. Blut 1981;43:389-392.

68 Kiefel V: The MAIPA assay and its applications in immunohaematology. Transfus Med 1992;2:181188.

69 Metcalfe P, Allen D, Chapman J, Ouwehand WH: Interlaboratory variation in the detection of clinically significant alloantibodies against human platelet alloantigens. Br J Haematol 1997;97:204207.
70 Menitove JE, Pereira J, Hoffman R, Anderson T, Fried W, Aster RH: Cyclic thrombocytopenia of apparent autoimmune etiology. Blood 1989;73: 1561-1569.

71 Carl B, Kroll H, Bux J, Bein G, Santoso S: B-lymphoblastoid cell lines as a source of reference DNA for human platelet and neutrophil antigen genotyping. Transfusion 2000;40:62-68.

72 Davoren A, Curtis BR, Aster RH, McFarland JG Human platelet antigen-specific alloantibodies implicated in 1162 cases of neonatal alloimmune thrombocytopenia. Transfusion 2004;44:1220-1225.

73 Morel-Kopp MC, Daviet L, McGregor J, Kaplan C: Drawbacks of the MAIPA technique in characterising human antiplatelet antibodies. Blood Coagul Fibrinolysis 1996;7:144-146.

74 Fagerstam LG, Frostell A, Karlsson R, Kullman M, Larsson A, Malmqvist M, Butt H: Detection of antigen-antibody interactions by surface plasmon resonance. Application to epitope mapping. J Mol Recognit 1990;3:208-214.
75 Chaiken I, Rose S, Karlsson R: Analysis of macromolecular interactions using immobilized ligands. Anal Biochem 1992;201:197-210.

76 Malmqvist M: Biospecific interaction analysis using biosensor technology. Nature 1993;361:186-187.

77 Myszka DG: Kinetic analysis of macromolecular interactions using surface plasmon resonance biosensors. Curr Opin Biotechnol 1997;8:50-57.

78 Kimura S, Yurugi K, Segawa H, Kuroda J, Sato K, Nogawa M, Yuasa T, Egawa $H$, Tanaka K, Maekawa T: Rapid quantitation of immunoglobulin $\mathrm{G}$ antibodies specific for blood group antigens A and B by surface plasmon resonance. Transfusion 2005;45:56-62.

79 Humphries MJ, Mould AP: Structure. An anthropomorphic integrin. Science 2001;294:316-317. 